\title{
Gang Member: Who Says? Definitional and Structural Issues
}

Authors: Smithson, H., Monchuk, L. and Armitage, R.

Dr. Hannah Smithson is a Senior Lecturer in Criminology - Manchester Metropolitan University, UK

Leanne Monchuk is a Research Assistant - University of Huddersfield, UK.

Dr. Rachel Armitage is a Reader in Criminology - University of Huddersfield, UK

\section{Abstract}

Owing to a number of high profile shootings in the UK over the past decade, there has been a significant amount of media and political interest in youth gangs. This chapter reports on a study conducted in 2009 in a large city in the North of England. It discusses the structure and formation of gangs in this city from the view of the young people identified as gang members and those responsible for this identification, i.e. police officers. Findings demonstrated that few of the young people viewed themselves as belonging to a gang, indeed many were scathing of such an attribution, contesting its applicability. A more accurate description of these young people is of a rather loose and fluid interlinked but informal social network of friends and associates. There was evidence that the authorities labeling of some young people as gang members and adoption and use of gang names attributed coherence and identity to what was often only fluid and transitional youth group formations. This may have created the very circumstances it sought to challenge. 


\section{Introduction}

The past decade has witnessed increased media interest and consequently political interest in the UK in youth gangs. This has mainly been a result of high profile shootings and stabbings attributed to gang activity. Despite this, British academics remain divided over the existence of delinquent gangs within the UK. There is a certain amount of reluctance to use the word 'gang' and 'gang member' in the UK (Hallsworth \& Young 2008; Alexander, 2008). Resolving this debate is made more difficult by the challenges of defining gangs and identifying their members and associates, a problem which has also plagued gang research in the USA. The conflation of labels such as 'gangs', 'delinquent youth groups' and 'organized crime networks' has added further confusion to the debate.

The purpose of this chapter is to outline the number of definitions which are being used across the UK and to explore how these definitions are perceived by practitioners and applied in practice. The chapter reports the findings of research conducted in a city in the North of England referred to as 'North City'. The aim of the study was to answer a number of broad ranging questions surrounding youth violence, including an exploration of young people's motivations to join a gang and become involved in the use of weapons, including firearms. This chapter reports the findings from this study and provides a discussion of the structure and formation of gangs in North City and encompasses the views of the young people identified as gang members and those responsible for this identification, i.e. police officers and representatives from a range of agencies and organizations (e.g.: Probation Service; Children's Services; Youth Services; Neighborhood Management.) 
Formal interviews were undertaken with 45 'gang members', their associates and key informants such as senior and operational police officers working in North City's specialist gang and firearm response unit. Findings demonstrated that few of the young people viewed themselves as belonging to a gang and contested the applicability of being labeled as such.

\section{Defining the Gang: The UK Experience}

In 2004, the Home Office defined delinquent youth groups as: 'youthful groups which have durability and structure and whose members spend time in public places and engage in delinquent activities together' (Home Office, 2004 p.1). By 2008 the Home Office, through the Tackling Gangs Action Programme (TGAP), was beginning to place greater emphasis on the use of guns with the definition:

'A group of three or more people who have a distinct identity (e.g. a name or badge/emblem) and commit general criminal or anti-social behavior (ASB) as part of that identity. This group uses (or is reasonably suspected of using) firearms, or the threat of firearms, when carrying out these offences' (Home Office, 2008 p. 23).

More recently in 2009, the Centre for Social Justice Working Group, a group comprised of '...prominent academics, practitioners and policy makers' (The Centre for Social Justice, 2009 p. 2) sought to apply a universal definition to be adopted by all those tackling gangs in order to end the confusion surrounding the terminology used within this arena and to allow comparative analysis between different studies. The group defined gangs as: 
'A relatively durable, predominately street-based group of young people who (1) see themselves (and are seen by others) as a discernible group, (2) engage in a range of criminal activity and violence, (3) identify with or lay claim over territory, (4) have some form of identifying structural feature and (5) are in conflict with other, similar gangs' (The Centre for Social Justice, 2009 p. 21).

In 2010 a Joint Thematic Review by the three HM Inspectorates of Prisons, Probation and Constabulary found that there were was no agreed working definition or common understanding of what constituted a gang amongst those working in a prison setting or in the community within the UK (HM Inspectorate of Prisons, 2010).

Of course we must also consider the development of the Eurogang definition and the implications of this definition for the development of UK policy and practice. They define a gang as: '...any durable, street-oriented youth group whose identity includes involvement in illegal activity" (Weerman et al, 2009 p. 20). The difference between the Eurogang definition and the definitions provided above is that the Eurogang approach is being used to produce comparable cross national data sets through the development of youth surveys which allow the measurement of each of the discerning characteristics within the definition. The UK's movement toward a common definition is promising, but the extent to which this is being applied by organizations and agencies such as the police, is questionable and remains inconsistent across the country. This incoherent approach to defining what constitutes a gang is highlighted by a number of UK based research projects which have been conducted to establish the extent and nature of gang involvement in the UK.

The Extent and Nature of Gang Involvement in the UK 
A number of UK based research projects have identified the presence of gangs. Stelfox (1998) for example, surveyed all UK police forces to explore the scope of gang activity across the UK. It is important to return to the notion of the complexities around defining a gang. These complexities were encountered by Stelfox (1998) whilst attempting to design the surveys to be sent to each of the police forces in the UK; 'there proved to be no generally agreed definition of a gang which was applicable to the UK situation which would serve as the basis for gathering data for this study' (p. 398).

Stelfox (1998) argues it was important the definition used in this study encompassed the use of criminal activity and consequently the definition used for his study included: 'Any group who uses violence or the threat or fear of violence to further a criminal purpose, but excluding football hooligans and terrorists' (Stelfox, 1998 p. 398).

Of the 48 forces that replied to the surveys, 16 identified gangs operating in their area. Across these forces, profiles of 71 gangs were returned. The majority of these gangs were composed of adult males. There was only one female gang. Two thirds of gangs were predominately white, one quarter was ethnically mixed and the remainder was predominately a single ethnic group. The average age range of the gang members was between 25 and 29 years old. Gang structures were typically loose, with no identifiable leader. Most engaged in a wide range of offences, although 17 per cent were described as offence specialists. Three quarters of gangs were involved in some sort of drug dealing. Most forces reported violence as the main problem associated with gangs. Sixty per cent of gangs allegedly possessed firearms. 
Decker (2001) argues that the concept of the gang has been distorted by the dominance of the view that gangs are well organized and tightly structured. Most UK research presents a picture of gangs that are disorganized and typically do not have leaders. Mares' (2001) ethnographic study of two gangs in Manchester illustrates this pattern. Both gangs were loosely organized and had no formal leaders. Mares (2001) does not outline the definition used within his study, however they '...were mostly ethnic street gangs involved in the same of drugs with strong intergang rivalry and high levels of violence' (Mares, 2001 p. 154). He describes the heavy involvement of both gangs in drug trading including heroin, crack and cocaine. There were about 90 members in each gang and the large majority was Afro-Caribbean in origin, which was representative of the ethnic composition of the area. The members were aged between 10 and 30 years old. Gangs found elsewhere in Manchester were all white and most gang members were aged less than 25 years old and some were as young as 10 years old.

Aldridge and Medina (2008), researching gangs in a Northern UK cityii, defined a gang as 'durable, street-orientated and have a group identity for which involvement in criminal activity is key' (Aldridge and Medina, 2008 p. 3). Similar to Mares' research they found that gangs were 'fluid, loose, messy and interlinked networks' (Aldridge and Medina, 2008 p. 4) very much like informal friendship groups. Interviews with the young people identified that they did not perceive themselves as having a 'membership' to a gang - but rather belonging to a social network where they would socialize with their peers. The ethnic composition of the gangs in this study reflected the areas in which they lived, although the authors note that only those from areas with a proportionally higher black minority received media and police attention. This study found evidence of violence, weapon carrying and drug 
trading, but the authors argue that gangs were in no way specialized in these activities.

In the research Bullock and Tilley (2002) conducted in Manchester, they defined a gang as:

'relatively enduring identifiable groups of young people who see themselves as members of those groups, and who commit crime as part of that membership' (p. 23).

Each of the four Manchester gangs that they studied had a core group of main players and a number of additional and associate members. A large majority of gang members were black and male and were heavily involved in criminal behavior, having on average, twelve prior arrests and two convictions. They committed a wide range of offences, including serious violent offences and property offences. Weapon carrying was common.

Bennett and Holloway (2004) adopt Klein's (2001) definition of a 'street gang' and 'youth gang' in their research. They summarize their research based on arrestees in Britain by suggesting that there are a variety of gangs, but that some common themes may be identified. These include the likelihood that gang members will be male, criminally active (particularly with regard to robbery and drug supply) and have a tendency to carry weapons including guns. Research also indicates that gang members are likely to be white and the dominant ethnic minority groups are Caribbean and Bangladeshi. However, these differences may be explained by the observation that gangs tend to reflect the ethnic composition of the areas from which they are drawn (Aldridge and Medina (2008); Esbensen and Weerman (2005). 
For the purposes of this chapter and in an attempt to explain and position our findings, we will focus on structural typologies of gangs as well as on definitional issues. Typologies are invaluable for understanding and delineating distinctly different categories of criminal groups. Klein and Maxson's (2006) typology of gangs as set out below will be utilized to explore the extent to which the young people involved in our study fit into any of these categories.

- Traditional gangs:

A traditional gang has usually been in existence for 20 or more years and continues to regenerate themselves. A traditional gang is a large, enduring, territorial gang with a wide age range and several internal cliques based on age or area.

- Neotraditional gangs:

A neotraditional gang resembles the traditional gang and is very territorial. However, a neotraditional gang has not been in existence as long, often for 10 years or less.

- Compressed gang:

A compressed gang represents a small gang comprising of up to 50 members. Unlike the traditional and neotraditional forms, there is an absence of territorially and sub-groups. It is also unclear whether they would grow into the more traditional forms. 
- Collective gang:

The collective gang looks like the compressed form but is bigger and with a wider age range. The collective form comprises of 100 members or less, they do not have developed sub-groups and may or may not be territorial. The form resembles a shapeless mass of adolescents and young adults and has not developed the distinguishing characteristics of other gangs.

- Specialty gang:

The specialty gang tends to be small with 50 or fewer members. It has developed a well-defined territory which may be based on residency or the opportunities for particular forms of crime. The principal purpose of a specialty gang is more criminal than social (p. 177-178).

\section{Research in North City}

\section{Overview}

The research was a 10 month study commissioned by a City Partnership Group responsible for North City's gun and gang crime strategy. Four areas in North City were identified by the commissioning body as the focus of the research. The areas will be referred to as Areas A, B, C and D. It is important to note that North City itself is amongst the most deprived cities in the UK with relatively high crime rates, low life expectancy and poor social cohesion. Each of the four research areas included 
within the study are characterized by these factors. Prior to outlining the methodology, it is important to contextualize the four areas which were focused

\begin{tabular}{|c|c|}
\hline Area A & $\begin{array}{l}\text { Area A has a population of over } 15,000 \text {, has a lower than average } \\
\text { household income for North City and a relatively high level of } \\
\text { unemployment. It has a comparatively high proportion of children } \\
\text { compared to the other areas in North City and nearly half of the } \\
\text { households comprise lone parent households. The crime rate in this area } \\
\text { is slightly lower than average compared to the average crime rate for } \\
\text { North City. }\end{array}$ \\
\hline Area B & $\begin{array}{l}\text { Area B has a population of over } 14,000 \text { and displays varying levels of } \\
\text { deprivation mixed with pockets of affluence. Unemployment levels in this } \\
\text { area are lower than other areas of North City and nearly } 30 \text { per cent of the } \\
\text { households comprise lone parent households. The crime rate in the area } \\
\text { is lower than average compared to the average crime rate for North City. }\end{array}$ \\
\hline Area C & $\begin{array}{l}\text { Area C has a population of } 14,000 \text { and is one of the more deprived areas } \\
\text { in North City. This area has the highest unemployment rate in North City } \\
\text { and over half of the households comprise lone parent households. The } \\
\text { crime rate in the area is higher than the average crime rate for North City. }\end{array}$ \\
\hline Area D & $\begin{array}{l}\text { Area } D \text { has a population of over } 14,500 \text { and like Area } C \text {, is one of the } \\
\text { more deprived areas in North City. It has a lower than average income } \\
\text { and higher than average unemployment rate and nearly half of the } \\
\text { households comprise lone parent households. The crime rate in Area D is } \\
\text { higher than the average crime rate for North City. }\end{array}$ \\
\hline
\end{tabular}




\section{Methodology}

The data described in this chapter derive from conducting semi-structured interviews with a total of 45 individuals across North City. The interviews were conducted by two researchers.

Fifteen interviews were conducted with practitioners, in the main, representatives from the multi-agency partnership group established to try and reduce levels of gang and gun crime in North City. The group consisted of senior police officers, front line youth workers and representatives from North City's Youth Service and Children's Service. Those interviewed were identified as the best placed to obtain information about North City's gang and gun crime strategy and information about each individual agency's role within the strategy.

Interviews were also conducted with thirty young people identified as being involved with gangs by the agencies outlined above. The young people were recruited for participation in several ways: referrals from North City's Youth Service and Probation Service; through ethnographic fieldwork and undertaking detached youth work and finally through prison interviews. The semi-structured interviews were undertaken using a narrative approach, which allowed respondents to present their life story. Prompts were used to gather specific information about life in the gang, motivations to become involved, methods of making money, use of weapons including firearms, levels of violence and desistance from the gang. The recruitment of the young people was undertaken in the four areas (Areas A, B, C and D).

The authors believe that the number of young people interviewed was considered to be sufficient for this study. It is important to reiterate at this juncture that the research 
study was commissioned, conducted and completed within a 10 month time period. A considerable amount of this time was used to identify, include and explore possible methods of recruiting young people. As discovered by Aldridge and Medina (2008), we also found that it was important to devote a considerable amount of time to establishing rapport and trust with the young people to be included in the research. It was evident that some of the young people were apprehensive as to whether or not we were actually police informants. To alleviate any concerns, we spent time establishing contact with the young people, attending youth clubs and accompanying youth workers on their detached work. We also reassured them that any information provided would remain anonymous and confidential. The interviews with the young people lasted between 30 minutes and 2 hours and were undertaken in a variety of venues, such as on the street, youth centers, houses, staff offices and prison rooms. All respondents were asked to read an information sheet and to sign a consent form prior to the interview commencing. All interviews were recorded, transcribed and then stored electronically. Due to the sensitivity of the research, a number of security safeguards were implemented. For example, passwords and encryption software were used to prevent unauthorized access to the files.

As described previously, the notion of gang membership is problematic. However, the sample of the 30 young people interviewed included 18 young people labeled as gang members, by police officers, youth workers or probation staff. The majority of these young people were either serving or had served prison sentences for gang related offences including firearm offences. Twelve 'associates' were also identified by the above agencies as being on the periphery of gangs and/or whose friends were involved in gang activity. Six of the sampled young people were, at the time, known to the gang and firearm specialist unit. They were individuals whom the gang 
and firearm specialist unit were observing or pursuing for gang and firearm related offences. All of the young people were aged between 16 and 29 years old. Twenty nine were male and one was female. All were White British in ethnic origin.

None of the young people were identified by us as gang members nor did they self identify as gang members. It was our task, as researchers, to explore the views of the young people with regard to the labels attached to them by agencies and their views on the existence of gangs and their membership of these gangs. The following sections draw together the conflicting views of young people and practitioners in North City.

\section{The Challenges of Defining the Gang within North City: The Practitioner's Perspective}

The challenges of defining gangs and gang involved young people were reflected by the practitioners interviewed. North City's partnership group does not have a common agreement about what constitutes a gang as the following quote demonstrates:

Not only is there not an agreed definition here in [North City], there's not an agreed definition in the country. Common sense would tell you that the TGAP [Tackling Gangs Action Programme] definition is a reasonable explanation of what a gang is, but in this area you know there's a lot of dysfunctional, disorganisation. Our groups of young males who we are terming 'gangs' and they themselves see themselves as being part of a gang but quite frankly we've got young kids who do nothing more than cause ASB [anti-social behaviour] and they're just being risk taking kids. 
Now would you say they're being a gang? Well the definition might lead you that way. So l'm not so sure that definition is crucial to looking at what we're doing. (Police Officer 1)

The difficulties in defining and identifying gangs are borne out by the fact that several practitioners admitted that they did not really know the extent of gang involvement in North City. One police officer was quite candid in this respect:

If you want my honest opinion I don't actually think we've got to the bottom of that. I have been a purveyor of an argument for quite some time now that we don't understand the gun crime and gang problem. (Police Officer 3)

A number of other practitioners were particularly robust in their claims that gangs did exist in North City. With one police officer stating the number of gang members the city was currently dealing with.

We're roughly dealing with about 102 people associated with gangs. That's it in terms of numbers. In terms of incidents, well we've seen a $47 \%$ reduction in firearm discharge that doesn't mean we're complacent, there are still some firearms out there. (Police Officer 5)

The above remarks return us to what for many respondents was a central issue, that the extent of gang and gun involvement in North City was heavily dependent upon how one was defining a gang. 
Our findings echo those of Decker and Kempf-Leonard (1991), their study attempted to find differences in the understanding of gangs amongst a number of different persons: police officers, members of an anti-drugs/anti-gangs task force and juvenile detainees. Interestingly, the police used the most narrow and restrictive definition of gang membership.

Despite the UK government's encouragement of practitioners and agencies to subscribe to the universal definition of a gang as set out in the 'Dying to Belong Report' published by The Centre for Social Justice (2009), it is clear in North City that this has not occurred. Of greater concern is the fact that practitioners in North City do not think that definition is crucial. This begs the question as to how practitioners identify young people as gang members and once they do, how gang members are then dealt with? Part of North City's gang and gun crime strategy was to devise intervention projects for gang related youths. Without a clear definition it is difficult to discern how such projects could be developed. The following sections demonstrate that although a common working definition was not in place, some young people living within the research areas in North City were identified as gang members. Moreover, practitioners were even creating names for groups of young people congregating together, based upon where they lived or where they chose to gather with their friends.

\section{What's in a name? The young people's perspective}

When young people were asked about the names given to local groups, their responses were very different. However, the majority felt strongly that these names had been given to groups of young people by the police and the media and that the 
young people themselves did not use these names. More importantly, the young people did not view themselves as being part of a gang.

Despite the police and media attention afforded to gangs in areas $A$ and $B$, not one of the young people interviewed from these areas referred to their groups by these names. In fact, they showed a great deal of contempt for the names:

There is no gangs. All that going on the '...' Gang and that like, there's no ' $\therefore$. Gang, do you think it is? Where do you think you are? We don't think we're fucking Bloods and Crips and Fucking Dutch and all this and that, what are you like? There are no gangs, you are all Muppets! (Young Person 4)

I laugh at it all the time I hear it, like the notorious '...' Gang. It was just a gang who hanged around in the ... and they called it the '..'. Gang. Everyone get mixed into them just cos you lived in .... Someone would say 'him there' and then the police would say, he's part of the '...' Gang. There might have been two or three groups at the .... (Young Person 26)

As mentioned above, many of the young people interviewed spoke about the fact that in their opinion, the police themselves had named gangs. It was mainly young people from Areas A and B who had held this opinion.

No-one goes round saying '...Gang' and '... Gang' and all that. You know what I mean? It's the police that make them up. Do you think kids are going to walk round like 'yeah, I'm in the ... Gang' and all that?...look like a little clown? (Young Person 4) 
It is instructive to note that despite the acknowledgement that the youths do not appear to view themselves as constituting a gang, they have still been labeled and received a name and are referred to by this name by the police and perhaps other agencies. This raises the question of how much labeled gang activity is due to the (mis)application of naming of what are otherwise young people using public space? This is discussed in the following quote from a young person:

As if kids are going to walk round doing that "I'm a gang" you're mad....police just drive past and see kids standing outside the [name of shopping centre] shops and think 'yeah that's the '...' gang because they are in the [name of shopping centre] and there's loads of them. (Young person 7)

This was also confirmed during an interview conducted with a police officer. As the police officer below alludes, most young people do not belong to gangs but can be mistaken for gang members or associates, by simply being observed in a particular area with other young people. Ralphs et al (2009) provide an enlightening account of this phenomena in their findings from research undertaken in an English City. Young people in this study were seemingly harassed and labeled as gang members simply because of the public space they occupied and the friends and associates they kept.

...the police are very quick to sort of say that these people are members of [a gang] because perhaps they're seen together when say just walking home from school or something and suddenly he is now a part of a gang. And there is nothing to base that on other than observations that people have seen but they haven't actually gone that stage further where they have been stopped because of some behaviour, it's that they have been seen together. (Police 3) 
Another police officer argued that the uniformity of dress and fashion among many young people, made them appear similar for stylistic reasons rather than gang membership. However, it was clear from the detached youth work we undertook and from the interviews with the young people, that the young people were not interested in any distinctive styles of dress and dressed much as any other young person in North City.

The young people interviewed felt labeling groups as gangs served to glamorize violence and encourage young people to aspire to be part of a gang. As one practitioner commented:

Someone was telling me a tale about a police officer asking a young person why he had joined a group and he said well, before I was in the group I was nothing, now I'm in the group I'm part of something. I am someone. So the kids are seeing it as getting an identity and respect. (Practitioner 6)

As noted by Howell (2007), media reporting can also exacerbate a gang problem. The media's portrayal of a high profile fatality, for example, may exacerbate the situation, contribute to the creation of a 'moral panic' and consequently exaggerate and misrepresent the scale of the actual gang problem. Furthermore, publicizing gang activity can perversely make that gang appear strong and thereby enhance their ability to intimidate and multiply (Ekblom, 2006), a consequence that was noted by one of the young people interviewed:

'...' never went round saying 'we're a gang' there were just fights know what I mean? Someone got jumped and then all of a sudden guns started being used and then the papers and the police started saying 
'....' gang. l've not once said I'm '...' or ‘ ... Crew, know what I mean? They're the ones that called us gangs, now all these kids in school are just looking and then all they see any time something happens in the paper is there's, like all the lads round by ours now they're all driving round in fast cars and fast motor bikes and they're only 13 and they're thinking I want a go. So it's their fault really with the gangs 'cos we never called our self a gang. (Young Person 1)

There was also an honest admission that agencies had added to the problem by inadvertently publicizing gangs and enhancing their reputations:

They [the police] should never have made us into gangs so they've got to take some responsibility. (Young Person 1)

It comes back to the issue I said right at the beginning when I said we never understand the problem. So how can we say we've solved it when we don't understand it? We gave the gangs credibility calling them '...' Crew and the '...'Gang'. We gave them the self publicity and credibility they required to associate. (Police Officer 2)

The young people's rebuttals to gang membership cannot be ignored. It would suggest that the gang label is indeed being either misapplied in some cases or overused. 


\section{Gang Structures in North City}

Decker (2001) argues that the concept of the gang has been distorted by the dominance of the view that gangs are well organized and tightly structured. Most UK research presents a picture of gangs that are disorganized and loosely structured which typically do not have leaders (Stelfox, 1998; Mares, 2001; Bullock and Tilley, 2002; Bennett and Holloway, 2004).

It is a similar situation in North City with practitioners believing that where gangs do exist in North City, they tend to be rather disorganized and unstable with unstructured membership patterns. The picture in North City is one of rather chaotic young people who have access to firearms rather than mature organized criminal gangs:

There is a natural assumption that they have a hierarchical structure which they can then attack using a variety of tactics. I actually believe in [North City] specifically we haven't got that. We have got groups of disenfranchised youths who associate on the basis of geography and past history between families... (Police Officer 4)

These perceptions of the loose structures of gang activity were reflected in the majority of responses from young people, few of whom talked about their group as organized with a hierarchical structure. The vast majority felt strongly that their group was not organized, had no structure and was simply a group of friends doing what they choose to do. This was particularly found in Areas A and B. Those who spoke of leaders or hierarchy were generally discussing this in the context of drug dealing, where someone would be in charge of supplying the drugs, leaving them to 'graft' 
(work) and then return the profits to their 'boss'. However, others did speak of 'top men' and 'leaders' when referring to group rivalries. This was evident more in Areas C and D.

Respondents from mainly Areas $A$ and $B$ expressed the view that groups within their area were not organized or structured and that there was no leader or 'boss' directing other members. The vast majority of participants highlighted that their gang was just a group of friends with no one in charge of activity.

Not as organised as they think really, it's all over the place to be honest with you. (Young person 14)

No that's what I mean we're, we're like, we're all of us, we're all equal you know what I mean? You don't get told by someone like the leaders to go and do something. (Young person 13)

It's just your mates innit? Just chill like, there is no leaders it's just like where you're from and that. (Young person 12)

Although their responses suggest that the groups are loosely organized and have no identifiable leader, a large number referred to 'older ones', who were usually in their late teens, early twenties and had expensive cars and nice clothes. The issue of leadership is ambiguous as although a named 'leader' may not exist, there may be a slightly more structured hierarchy than becomes apparent through the young people's responses.

There's no leader who tells us what to do like, but there's the older people who have us doing stuff for them innit? (Young person 9) 
If we use Klein and Maxson's (2006) typology it could be concluded that the structures in Areas A and B are best described as collective gangs:

'Size can be under 100 but is probably larger...it has not developed subgroups and may or may not be a territorial gang....resembles a kind of shapeless mass of adolescents and young adult members and has not developed the distinguishing characteristics of other gangs'. (p. 177-178)

In contrast to Areas $A$ and $B$, young people living in Areas $C$ and $D$ spoke of fairly rigid structures and of hierarchies.

Interviewer 1: So the only way gangs would stop, you were saying, is if you take their...?

Respondent: [Agreement noise]

Interviewer 1: If their top man...

Respondent: Yeah, when we take down their leaders

(Young person 16)

and

Yeah, yeah they [the leaders] own everything, they own every little kid and everything, every little kid you see running round and all that they own everything. (Young person 18)

Young people in Areas C and D spoke of 'top' families 'owning' the area. Hobbs (2001) refers to family firms as: 
‘...long established families who had retained a considerable degree of hegemony within the neighborhood...' (p. 551).

He describes family firms as owning areas in the 1960s but suggests that these firms have greatly diminished (Hobbs, 2001). However, our findings indicate that these family firms may still be in existence in parts of North City, particularly in Areas C and D. This extract between a young person and one of the interviewers is the clearest example of this finding:

Respondent: They're the second from top [name of family].

Interviewer 1: Oh okay so they're not the top because a lot of people say that they're like the top but they're not quite?

Respondent: No

Interviewer 1: They're just underneath the top?

Respondent: Just underneath yeah

Interviewer 1: So if there's someone else there, then the [name of family], so where does your family come?

Respondent: I wouldn't even have a clue innit, l'd myself, l'd rank myself higher innit but I don't know.

Interviewer 1: You'd rank yourself higher than?

Respondent: Not the [name of family] no. They're just crazy man. 
Klein and Maxson's (2006) traditional gang typology may also be a useful way of explaining the apparent rigid structure of areas $C$ and $D$ :

“...generally been in existence for 20 or more years; they keep regenerating themselves....a large, enduring, territorial gang with a wide age range and several internal cliques based on age or area" (p. 176-177).

This contrasts with much of the research undertaken in the UK with the groups in Areas $C$ and $D$ being quite different from the gangs typically depicted in UK research which can be found in Areas A and B of North City. Owing to this finding, it is clear that in North City a 'one size fits all' approach to prevention and intervention cannot be adopted as there appears to be at least two distinctly different categories of groups. Undertaking further research in North City over a greater period of time, may indeed identify more categories.

\section{Group Territories and Rivalries within North City}

Kintrea et al (2008) in their study of 'Young People and Territoriality in British Cities' defined territoriality as 'a social system through which control is claimed by one group over a defined geographical area and defended against others' (p.1). Case studies showed that territoriality was important in the lives of many young people, although it was manifested in various forms - from young people who socialised on the streets; to groups with a stronger territorial affiliation, some of whom identified themselves as a gang; to more highly organised, criminally-oriented territorial gangs. Territoriality often gave rise to physical conflict between groups of young people.

Although we are not suggesting that territoriality is a defining characteristic of gangs, our research certainly identifies that in many instances, territory was the rationale 
behind rivalries and violence amongst young people in each of the four areas. We found as did Kintrea et al (2008) that territoriality was manifested in various forms. Practitioners reported that in Areas A and B gangs were involved in dealing drugs (primarily cannabis according to one source), and were primarily motivated by an historic rivalry of two groups who were loosely associated. The importance of local rivalries was apparent from the interviews with young people. The ethnographic nature of the study and the time spent in the areas by the research team enabled us to build a geographical picture of these territorial issues. It became abundantly clear that in most instances territory and rivalry could be explained by living on one side of a road compared to another or being from adjacent housing estates.

Many of the young people from Areas A and B were adamant that it was too dangerous for them to venture into the opposing area. Many stated that the only way that they could, would be to travel by car. The extract below illustrates this mentality clearly:

Interviewer 1: So you wouldn't go to [Area A]?

Respondent: I wouldn't go there no. Not unless I was in a car or something like that, I wouldn't walk through there.

Interviewer 1: Right. And is it because people would know that you lived in $[$ Area $\mathrm{B}]$ ?

Respondent 1: Yeah. I can go there but I just, I wouldn't just walk through it, know what I mean? Because I know I'm going to get fucked. 
Territorially was discussed by a number of young people who were interviewed from Areas $C$ and $D$, confirming their classification as a 'traditional gang' as described earlier. The following quotes from respondents in these two areas clearly highlight this.

Respondent: The people shooting at us who we've got a beef with.

We've got our own little patch and they've got their own little patch.

Interviewer 1: So where's your patch?

Respondent: ' ....' Road and '...'.

Interviewer 1: How far away from one other are these two patches?

Respondent: About 5 minutes.

(Young person 24)

One young person from Area $\mathrm{D}$ agreed that the issue of territoriality was an instigator for violence and even described how this territorial claim could be determined by which road you travel on.

Interviewer 1: Is it more like an area?

Respondent: Roads. You are talking roads not areas. It's scary...I have been in situations, I have been there and someone has drove past me on a bike and pointed and the only reason why they wouldn't let that thing off [and use a firearm] was because their cousin was standing next to me. 
The aspect of territoriality was epitomized by a comment made by a young person from Area D.

'Ninety-nine percent of the time they remain in their area, in their segregated little piece of land...they're living in and most of their little brothers do, they're all in one area...it's very rare you'll see them in [in another area]...you probably will see them occasionally but it's very rare you see them branching out of their area, it's unusual...' (Young person 2)

Without doubt, the closed environments that many of the young people occupied in each of the four areas generated a strong parochial identification, local loyalty and sense of belonging and this without question promoted territorial disputes between rival areas.

\section{Conclusion}

Current gang definitions point to a degree of durability and structure to groups, but are vague regarding the degree of structure that constitutes a gang. Most UK and US research presents a picture of gangs that are disorganized and typically have no leaders - hence the Eurogang paradox. Our findings suggest that North City is in the main no different. Overall, respondents suggested that gang activity tended to be low level, disorganized and limited to small geographical areas.

Crucially, in contrast to currently accepted definitions, we found little evidence that groups of young people living in the four areas of North City had a 'distinct identity' but perhaps more crucially that they did not define themselves as a discernable 'gang.' Rather they were defined and labeled as gang members by the police and 
other relevant organizations. Young people in some of the areas may have resigned themselves to accepting the gang label but the questions remains as to whether they were engaging in what agencies were labeling as gang activity.

Our findings have led us to question (not conclude), given the current UK political and policy fixation with youth gangs, whether consideration should be given to dropping the use of the term gang as a helpful explanation of youth violence and delinquency in the UK. This difficulty was highlighted by UK Youth Offending Service workers, interviewed as part of the Youth Justice Board's report into gangs, who expressed grave concerns over what they saw as the indiscriminate use of the term gang. They argued that many young people take part in group offending but they would not necessarily class themselves as being part of a gang (YJB, 2007). The Youth Justice Board suggested the use of the term 'delinquent youth groups' rather than 'gangs' to more accurately describe youth networks (YJB 2007).

It is unlikely that the term gang will be replaced which makes the issue of employing a robust and consistent definition of central importance. It is clear that any definitions employed will have a significant impact on estimates of the size and nature of the gang problem; how young people are targeted and selected to become involved in a range of interventions designed to curtail their gang involvement and perhaps more importantly, the means by which gang involved young people are treated within the criminal justice system. 


\section{References}

Aldridge, J., and Medina-Ariza, J., (2007) Youth Gangs in an English City: Social Exclusion, Drugs and Violence University of Manchester. Research report ESRC RES-000-23-0615. 16-01-2008.

Alexander, C (2008) 'Re'-thinking 'Gangs'. Report prepared for the Runnymeade Trust. ISBN-13: 978-1-9067320-1-1 (Online). Available from: www.blackeducation.info/upload/docs/RethinkingGangs-2008.pdf [Accessed 23 November 2010]

Bennett, T. and Holloway, K. (2004) 'Gang Membership, Drugs and Crime in the UK' British Journal of Criminology, 44 (3) pp. 305-323.

Bullock, K. and Tilley, N. (2002) Shootings, Gangs and Violent Incidents in Manchester: developing a Crime Reduction Strategy. Crime Reduction Research Series Paper 13. London: Home Office.

Decker, S.H. (2001) 'The impact of organizational features on gang activities and relationships' in M.W. Klein, H.J. Kerner, C.L.Maxson and E.G.M. Weitekamp, eds., The Eurogang Paradox: Street Gangs and Youth Groups in the U.S. and Europe. London: Kluwer Academic Publishers.

Decker, S. \& Kempf-Leonard, K. (1991) Constructing Gangs: The Social Definition Of Youth Activities. Criminal Justice Policy Review 5: 271

Ekblom, P. (1999). 'Can We Make Crime Prevention Adaptive by Learning from Other Evolutionary Struggles' Studies on Crime and Crime Prevention 8 (1): 27-51. Cited in Felson, M. (2006) Crime and Nature. Thousand Oaks: Sage. 
Esbensen, F-A. and Weerman, F.M. (2005) 'Youth gangs and troublesome youth groups in the United States and the Netherlands: a cross national comparison', European Journal of Criminology, 2, 5-37.

Hallsworth, S., and Young, T. (2008) 'Gang talk and gang talkers: A critique', Crime, Media, Culture, 4, (2): 175-195.

HM Inspectorate of Prisons (2010) The Management of Gang Issues among children and young people in prison custody and the community: a joint thematic review. London: HM Inspectorate of Prisons.

Home Office (2004) Delinquent Youth Groups and Offending Behaviour: findings from the 2004 Offending, Crime and Justice Survey. London: HMSO.

Home Office (2008) Tackling Gangs: A Practical Guide for Local Authorities, CDRPs and other local partners. London: HMSO

Hobbs, D. (2001) 'The Firm: Organizational Logic and the Criminal Culture on a Shifting Terrain' in British Journal of Criminology, 41 pp 549-60.

Howell, J.C. (2007) 'Menacing or Mimicking? Realities of Youth Gangs' Juvenile and Family Court, 58, (2) pp. 39-48.

Kemshall, H., Mackenzie, G., Wood, J., Bailey, R., and Yates, J. (2005) Strengthening Multi-Agency Public Protection Arrangements (MAPPAs). Home Office Development and Practice Report. London: Home Office.

Kintrea, K., Bannister, J., Pickering, J., Reid, M \& Suzuki, N. (2008) Young people and territoriality in British Cities. Joseph Rowntree: October. 
Klein, M. (2001) 'Resolving the Eurogang Paradox' in M. W. Klein, H.J. Kerner, C. L. Maxson and E. G. M Weitekamp (eds) The Eurogang Paradox: Street Gangs and Youth Groups in the US and Europe. London: Kluwer Academic Publishers.

Klein, M.W.,Weerman, F and Thornberry, T.P. (2006) 'Street Gang Violence in Europe' European Journal of Criminology. 3 (4): 413-437.

Klein, M.W. and Maxson, C.L (2006) Street gang patterns and policies. New York: Oxford University Press.

Stelfox, P. (1998) 'Policing Lower Levels of Organised Crime in England and Wales', The Howard Journal, 37 (4) 393-406.

Mares, D (2001). 'Gangstas or Lager Louts? Working Class Street gangs in Manchester' in Klein, M.W., Kerner, H-J., Maxson, C. \& Weitekamp, E.G.M. (2001) (Eds). The Eurogang Paradox: Street Gangs and Youth Groups in the U.S. and Europe. Dordrecht: Kluwer. pp 153-164.

Ralphs, R., Medina, J and Aldridge, J. (2009) Who needs enemies with friends like these? The importance of place for young people living in known gang areas. Journal of Youth Studies, 12:5, 483-500.

The Centre for Social Justice (2009) Dying to Belong: An In-depth Review of Street Gangs in Britain. London: The Centre for Social Justice.

Weerman, F. M., Maxson, C.L., Esbensen, F., Aldridge, J., Medina, J., and Gemert, F. (2009) Eurogang Program Manual: Background, development, and use of the Eurogang instruments in multi-site, multi-method comparative research. Available 
online at: http://www.umsl.edu/ ccj/eurogang/Eurogang_20Manual.pdf [Accessed 3rd June 2011].

Youth Justice Board (2007) Groups, Gangs and Weapons. London: YJB. 
i The name of the city has been changed to protect the anonymity of the city and all the participants who took part in the research.

ii This city was not North City. 